\title{
Presentation and management of congenital heart disease in the first year of age
}

\author{
Presentación y manejo de las cardiopatías congénitas en el primer año de edad
}

\author{
Rocío A. Peña-Juárez* , Carlos Corona-Villalobos², Miguel Medina-Andrade1 , Luis Garrido-García², \\ Carlos Gutierrez-Torpey², and Moisés Mier-Martínez² \\ ${ }^{1}$ Department of Pediatric Cardiology, Hospital General de Occidente, Zapopan, Jal.; ${ }^{2}$ Cardiology Department, Instituto Nacional de Pediatría, Mexico \\ City, Mexico
}

\begin{abstract}
Congenital heart disease (CHD) is defined as a structural abnormality of the heart or large intrathoracic vessels. They constitute the most frequent congenital malformation at birth. At least one third of patients require some type of intervention before the year of age. The clinical manifestations of heart disease in the neonatal stage are presented with a wide clinical context and can be confused with problems at the pulmonary or infectious level making difficult to diagnose them and thereby contributing significantly to the mortality and morbility of these patients since the diagnosis is delayed and timely handling. Pulse oximetry monitoring in the neonatal period is currently used as a diagnostic method for the detection of critical congenital heart disease. Although it detects them early, in many countries it is not yet carried out. The objective of this article is to offer an overview of the clinical presentation, diagnostic aspect, and initial management of CHD in the first year of age that may be useful to first contact physicians to improve the management of this group of patients.
\end{abstract}

Key words: Congenital heart. Cardiovascular diagnostic technique. Prostaglandins.

\section{Resumen}

Las cardiopatías congénitas (CC) se definen como una anomalía estructural del corazón o de los grandes vasos intratorácicos. Constituyen la malformación congénita más frecuente al nacimiento. Al menos un tercio de los pacientes requieren algún tipo de intervención antes del año de edad. Las manifestaciones clínicas de las cardiopatías en la etapa neonatal se presentan con un amplio contexto clínico y se pueden confundir con problemas a nivel pulmonar o infeccioso, lo que dificulta su diagnóstico y con ello contribuyendo de forma importante a la mortalidad y morbilidad de estos pacientes, ya que se retrasa el diagnóstico y manejo oportuno. El monitoreo por oximetría de pulso en el periodo neonatal se utiliza actualmente como método diagnóstico para la detección de cardiopatías congénitas críticas; a pesar de que las detecta en forma temprana, en muchos países aún no se lleva a cabo. El objetivo de este artículo es ofrecer un panorama general de la presentación clínica, aspectos diagnósticos y manejo inicial de las CC en el primer año de edad que pueda ser de utilidad a los médicos de primer contacto para mejorar la atención en este grupo de pacientes.

Palabras clave: Cardiopatía congénita. Técnica diagnóstica cardiovascular. Prostaglandinas.

\section{Correspondence:}

*Roció A. Peña-Juárez

E-mail: alepejz@gmail.com
Available online: $20-10-2021$ Arch Cardiol Mex (Eng). 2021;91(3):303-312 www.archivoscardiologia.com 2604-7063 / @ 2020 Instituto Nacional de Cardiología Ignacio Chávez. Published by Permanyer. This is an open access article under the CC BY-NC-ND license (http://creativecommons.org/licenses/by-nc-nd/4.0/). 


\section{Introduction}

The definition for congenital heart disease (CHD) varies widely among epidemiological reports of the disease. In this review, we adhere to the definition proposed by Mitchell et al., as "a gross structural abnormality of the heart or intrathoracic great vessels that is actually or potentially of functional significance"1. CHD constitutes the most common congenital malformation ${ }^{2}$, with an incidence of 2.5 to 3 per 1,000 births $^{3,4}$. Global prevalence in 2000 was 11.9 per 1,000 births $^{5}$. At least one third will require some type of intervention within the first month of life ${ }^{6}$, with a high mortality risk if there is no timely diagnosis. Its clinical presentation has a broad context; the cardinal presentation of cyanosis, shock and heart failure can be confused with lung or infectious problems, which delays diagnosis and, therefore, doctors who care for these patients must establish a wide range of differential diagnoses and consider CHD when a critically ill neonate is managed ${ }^{7}$. Monitoring by pulse oximetry is used as a screening method for the detection of critical congenital heart disease (CCHD) ${ }^{8}$; however, despite the fact that the American Academy of Pediatrics (AAP) and the American Heart Association (AHA) recommend $i^{9}$, in many hospitals, the material that is required to perform the test is unavailable. Advances in the treatment of children with $\mathrm{CHD}$ have been remarkable, with a significant decrease in surgical mortality (from $15 \%$ in 1990 to $5 \%$ in 2000 ), secondary to early detection, surgical techniques, and preoperative and postoperative care ${ }^{10}$. However, in many hospitals there is no multidisciplinary team available for the care of these conditions. That is why doctors who are the first contact for the care of these patients require training for $\mathrm{CHD}$ screening and timely management. The purpose of this article is to provide an overview of $\mathrm{CHD}$ clinical characteristics, diagnosis and initial management that may be useful for improving the care of these patients. For practical purposes, the article will be divided in two parts: the first one includes the neonatal stage, and the second, the infant stage.

\section{Neonatal stage}

\section{What to do with the suspicion of a newborn with congenital heart disease?}

It is essential for a proper anamnesis to be obtained, in order to know the characteristics of pregnancy and delivery. A thorough physical examination should be carried out, including blood pressure and palpation of pulses in all four extremities. If there are data consistent with $\mathrm{CHD}$, there are screening tests; the two most widely used methods are:

- Pulse oximetry. It is performed in asymptomatic newborns at between 24 to 48 hours of life or one hour prior to discharge. Its purpose is to detect CCHD, and it is a non-invasive, low-cost tool ${ }^{9}$. The test consists of oximetry measurement at the right upper extremity and either lower extremity (pre-ductal and post-ductal); however, there are heart diseases with right aortic arch, which is why measuring oxygen saturation ( $\mathrm{SaO} 2)$ in both arms and either foot is recommended. A result is abnormal if: a) saturation is < $90 \%$; b) $\mathrm{SaO} 2<95 \%$ in both extremities on three measurements separated by 1 hour, or c) absolute difference $>3 \%$ between hand and foot in all three measurements, each one separated by one hour ${ }^{9,11}$.

- Hyperoxia test. It is performed in cases where differentiating between lung or heart pathology is required. Children with lung disease have decreased alveolar oxygen concentration and many times alveolar-arteriolar gradient is increased, which is not observed in $\mathrm{CHD}^{12}$. Hyperoxia test can be performed to differentiate the cause of desaturation, which is indicated in neonates with saturations $<95 \%$. The purpose is to study partial pressure of oxygen $\left(\mathrm{pO}_{2}\right)$ response in arterial blood after administration of $100 \%$ oxygen for a 10 -minute period. A baseline $\mathrm{pO}_{2}$ measurement of right radial artery (pre-ductal) and an artery of the lower extremity (post-ductal) should be obtained with the child breathing ambient air (fraction of inspired oxygen $\left[\mathrm{FiO}_{2}\right.$ of $\left.21 \%\right)$ and then a new measurement after administration of $100 \%$ oxygen $\left(\mathrm{FiO}_{2}\right.$ of $\left.100 \%\right)$. When the origin of cyanosis is pulmonary, $\mathrm{pO}_{2}$ increases up to $100 \mathrm{mmHg}$. But with a right-to-left intra-cardiac shunt, arterial $\mathrm{pO}_{2}$ does not exceed $100 \mathrm{mmHg}$ and the increase is not greater to 10 $30 \mathrm{mmHg}$. A pO $\mathrm{P}_{2}$ lower than $70 \mathrm{mmHg}$, elevations of less than $30 \mathrm{mmHg}$ or unchanged $\mathrm{SaO}_{2}$, frankly points at a cardiogenic cause; rarely do CCHDs show an increase in arterial oxygen concentration to more than $150 \mathrm{mmHg}$ when exposed to $100 \%$ oxygen. Although $\mathrm{FiO}_{2}$ at $100 \%$ is only achieved with the patient intubated, there is a practical test where oxygen is administered at 10 liters/minute for 10 minutes to assess the saturation response. If $\mathrm{SaO}_{2}$ on oximetry does not increase to more than 
$95 \%$, measurement by arterial blood gas is not necessary ${ }^{12}$.

\section{What type of heart disease does the patient have?}

There are multiple CHD classifications; however, understanding the types of $\mathrm{CHD}$ and their management requires taking some cardiovascular physiological basic points into account. Cardiac physiology hemodynamic principles are based on fluid mechanics and hydrodynamics basic principles. These concepts are essential for pulmonary-systemic circulation relationships to be understood, which it is crucial for CHD proper care ${ }^{13}$.

Cardiac output is defined as the volume the heart pumps per time unit; two of its basic components are systemic and pulmonary blood flow, with the quotient between both being 1. The reference method for measuring pulmonary flow-systemic flow quotient ( $p Q: s Q$ ) is the Fick method, which consists of oxygen concentration measurement in blood samples obtained by catheter from different points of pulmonary and systemic circulation after 10 minutes of breathing $21 \%$ oxygen; it is calculated as:

$\mathrm{Q}(\mathrm{L} / \mathrm{min})=\mathrm{O}_{2}$ consumption $(\mathrm{mL} / \mathrm{min}) / \mathrm{O}_{2}$ arteriovenous difference $(\mathrm{mL} / \mathrm{L})$

This way, oxygen concentration decrease or increase secondary to an intrapulmonary or intra-cardiac shunt or due to ventilation/perfusion alteration can be characterized. Measurement of the quotient between pulmonary and systemic output informs on integrity of the independence between both these circulations ${ }^{14}$.

$-\mathrm{sQ} \rightarrow$ systemic flow.

$-p Q \rightarrow$ pulmonary flow.

$-p Q: s Q \rightarrow$ flow ratio:

- $\mathrm{pQ}: \mathrm{sQ}=1 \rightarrow$ normal.

- $p Q: s Q<1 \rightarrow$ heart disease with decreased pulmonary flow (alteration in ventricular-pulmonary flow continuity and patent ductus arteriosus) $)^{14,15}$.

- $p Q: s Q>1 \rightarrow C H D$ with increased pulmonary flow, there is systemic blood passage into pulmonary circulation.

Traditionally, we are taught the $\mathrm{T}$ and $\mathrm{H}$ of cyanotic $\mathrm{CHD}$ by their acronyms. They include: tricuspid atresia (TA), tetralogy of Fallot (TOF), transposition of the great arteries (TGA), truncus arteriosus communis (TAC), total anomalous pulmonary venous return (TAPVR) and hypoplastic left heart syndrome $(\mathrm{HLHS})^{16}$. However, the variety of lesions that have cyanosis is beyond the scope of this list, which is why it is best to emphasize the understanding of CHDs pathophysiology by using the clinical presentation to reduce differential diagnoses and improve management. The classification based on clinical characteristics and management is shown in figure 1. For this, patients are divided in two large groups, each one with subtypes:

The first step is to determine the presence or not of cyanosis:

- Cyanosis. It is a bluish coloration of skin and mucous membranes secondary to poor oxygenation due to cardiac or pulmonary causes. It is caused by the presence of deoxygenated blood at the capillary level. Neonates may exhibit transient peripheral cyanosis (acrocyanosis), which can occur in children with normal anatomy and cardiac function as a result of benign conditions such as exposure to cold, and other severe non-cardiac conditions, such as sepsis. Central cyanosis includes mucous membranes, lips or trunk; it is always pathological ${ }^{17}$. Cyanosis depends on the degree of arterial desaturation in the first place, and total amount of hemoglobin and cardiac output. Interrelationship of these three factors can be assimilated with the following mathematical formula:

Hemoglobin $=\mathrm{K}$

$$
\frac{- \text { Hemoglobina }=\mathrm{K}}{-\mathrm{VMC} \times \mathrm{SaO}_{2}}
$$

Cardiac output $x \mathrm{SaO} 2$

Where cyanosis will be directly related to hemoglobin total amount and indirectly related to cardiac output and arterial oxygen saturation. This explains Lundsgaard and van Slyke hypothesis, who consider that there should be 5 grams of hemoglobin reduction in peripheral capillary circulation in order for it to be observed ${ }^{1}$. In practical terms, hemoglobin dissociation curve shifts make the diagnosis of cyanosis based on skin coloration inaccurate; therefore, it is highly important for the oximetry test to be performed in order to avoid CCHD underdiagnosing.

Newborns with cyanotic heart disease require immediate management even while waiting for cardiologic assessment or transfer. Newborns with cyanotic CHD are divided in two categories:

- Cyanosis with shock. There is important cardiovascular involvement and constitutes a neonatal emergency. These are CHDs with inadequate mixture (TGA with intact interventricular septum, obstructed TAPVR). Patients exhibit a poor general condition, with data consistent with low cardiac output and metabolic acidosis, starting abruptly within the first 72 


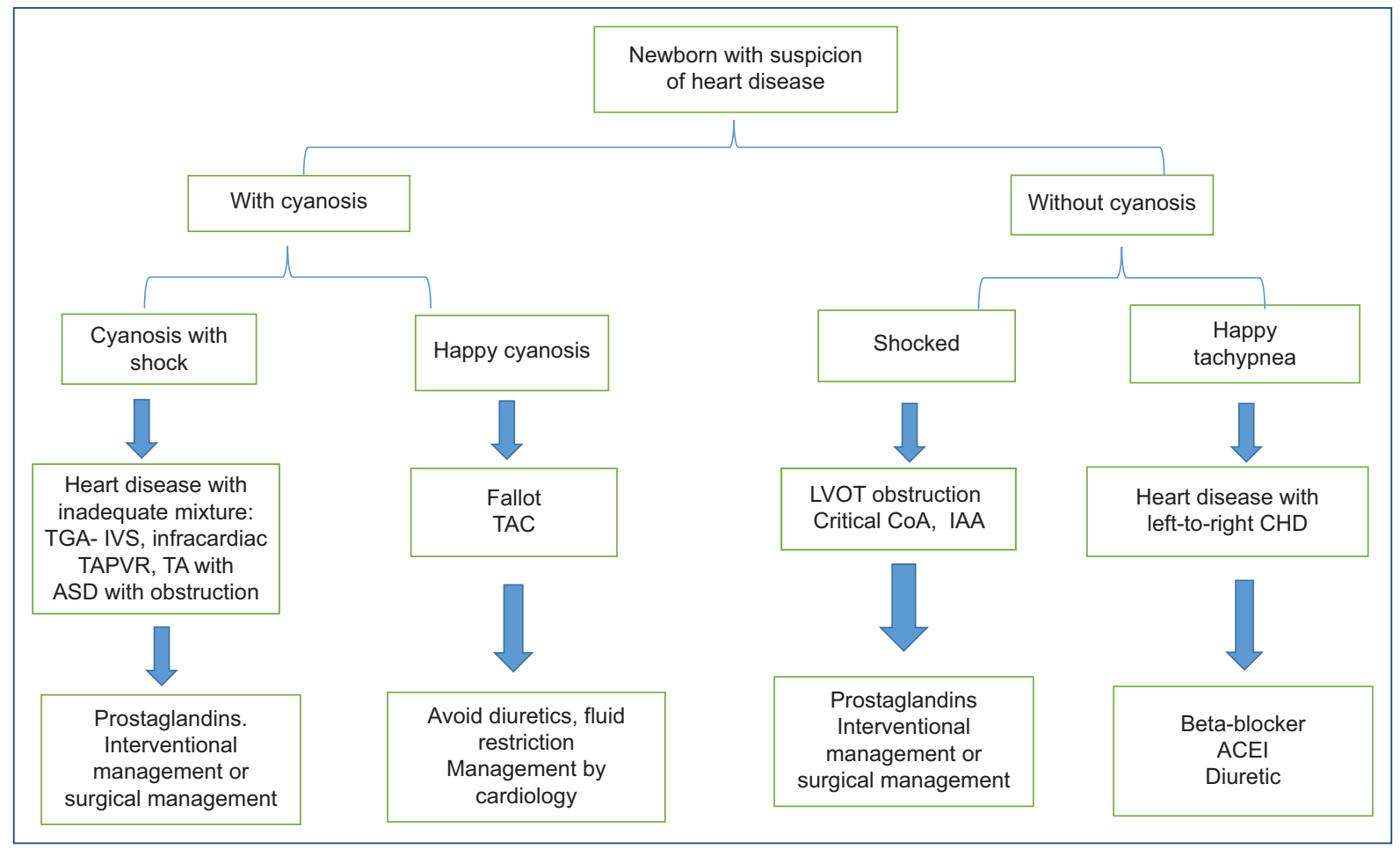

Figure 1. Algorithm for the diagnosis and management of the newborn with suspected heart disease.

TGA-IVS: transposition of the great arteries with intact interventricular septum; TAPVR: total anomalous pulmonary venous return; TA: tricuspid atresia; ASD: atrial septal defect; TAC: truncus arteriosus communis; CoA: coarctation of the aorta; IAA: interrupted aortic arch; LVOT, left ventricular outflow tract; CHD: congenital heart disease; ACEI inhibitors: angiotensin-converting enzyme inhibitors.

hours. Findings on chest X-ray are varied and depend on the type of CHD; if it is a TGA, it can be normal or the typical egg/oval-shaped cardiac silhouette (secondary to a narrow mediastinum) and have increased pulmonary flow ${ }^{18}$. Patients with obstructed TAPVR show right atrial and ventricular growth, the pulmonary artery arch is prominent, cardiomegaly is minimal or absent and data consistent with severe venocapillary hypertension are perceived ${ }^{19}$. This type of $\mathrm{CHD}$ is known as CCHD and its management requires immediate procedures to remove the obstruction $^{16}$. In this group, arterial duct deserves to be specially mentioned, since many of these heart diseases are duct-dependent. It should be borne in mind that, after birth, the arterial duct functionally closes at between 24 and 72 hours and, anatomically, at 1014 days $^{20}$; prostaglandins are used to avoid its closure.

- Happy cyanosis. Cyanosis with tachypnea without respiratory distress. Clinical decompensation is later, about a few weeks or even months later, since patients initially have adequate pulmonary and systemic flow; however, as pulmonary vascular resistances decrease, there is pulmonary over-circulation, which results in heart failure ${ }^{16}$ (Fig. 2). The main heart diseases in this group are TOF, TAC and unobstructed anomalous pulmonary venous return. TOF is the most common cyanogenous CHD, and the degree of cyanosis depends on the degree of pulmonary artery obstruction, either by stenosis or atresia; if it is an atresia or severe stenosis, patients exhibit saturations $<75 \%$ without response to the hyperoxia test, and since these conditions are duct-dependent, they are treated with prostaglandins $^{16}$. If obstruction is mild (pink Fallot), pulmonary vascular resistances will decrease during the first few weeks of life, causing larger pressure difference between both ventricles with pulmonary over-circulation and persistent cyanosis ${ }^{21}$. In brief, this group of patients may have no cyanosis at birth or have a positive oximetry test.

- Without cyanosis. It is divided in two types:

- Shock. Patients have significant cardiovascular compromise, with data consistent with 


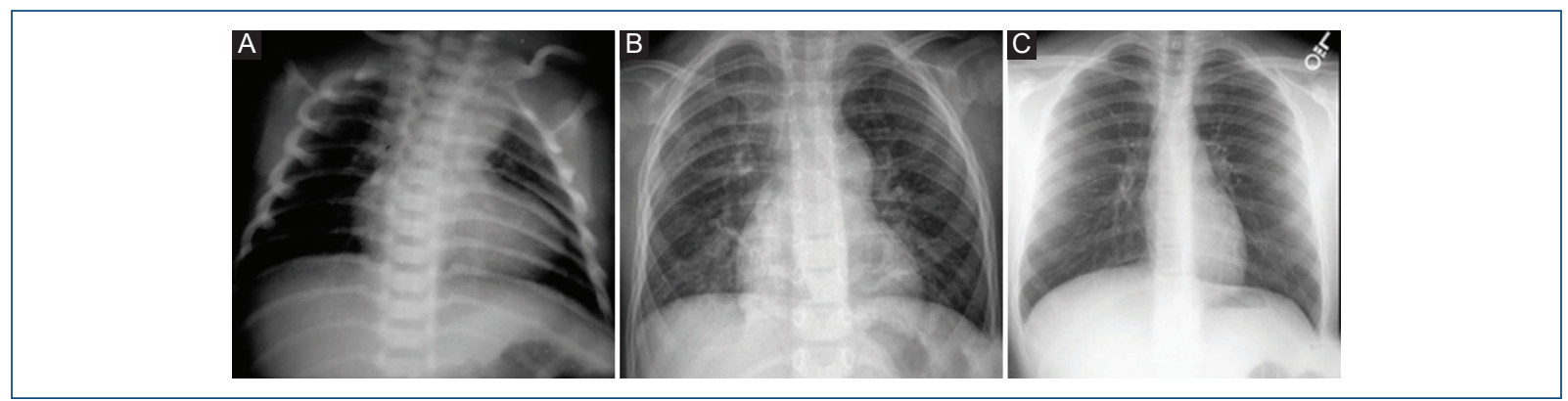

Figure 2. A: X-ray with decreased pulmonary flow, typical of a patient with tetralogy of Fallot. B: X-ray with increased pulmonary flow and prominent pulmonary artery trunk of a patient with ventricular septal defect. C: X-ray with normal pulmonary flow.

hypoperfusion and cardiogenic shock. Symptoms have a sudden onset within the first 72 hours of life coinciding with arterial duct closure ${ }^{22}$; these cases are CCHD, since patent ductus arteriosus replaces systemic flow from the pulmonary artery to the aorta in lesions with left ventricular outflow tract important obstruction such as critical coarctation of the aorta, HLHS and interrupted aortic arch. Diagnostic suspicion is essentially clinical, after physical examination with blood pressure measurement and pulse evaluation ${ }^{22}$, given that, on many occasions, an important differential between pre-ductal and post-ductal blood pressure can suggest left side duct-dependent obstructive lesion, such as critical coarctation or critical stenosis of the aorta ${ }^{7}$. Chest X-ray shows cardiomegaly and pulmonary edema. Management is comprehensive and requires diuretics, metabolic acidosis correction ${ }^{22}$, inotropic drugs, prostaglandins and some interventional or surgical procedure. Main differential diagnosis is sepsis, due to the similarity with clinical characteristics.

- Happy tachypnea. Clinically, patients exhibit tachypnea without other data consistent with respiratory failure. Clinical presentation is late, coinciding with the drop of pulmonary resistances. Tachypnea is accompanied by data consistent with heart failure. Generally, it is caused by pathologies with left-to-right shunt, with heart diseases being more common; as previously mentioned, they cause increased pulmonary flow, heart cavities dilation, heart failure, pulmonary hypertension initially by hyperflow and, if this hypertension is not treated in a timely manner, it can progress to be secondary due to increased pulmonary resistances, which eventually causes
Einsenmenger syndrome ${ }^{23}$. In these patients, initial administration of oxygen or pulmonary vasodilators increases pulmonary flow, which causes heart failure and acute pulmonary edema; therefore, the management of this group is based on preload decrease. Chest $X$-ray shows cardiomegaly with increased pulmonary flow $(p Q>s Q$ ) (Fig. 2). The classification based on clinical characteristics and management is shown in figure 1.

\section{How is the newborn with congenital heart disease managed?}

Management is based on the group they belong to. If the newborns exhibit cyanosis with shock, these are severely ill patients with a CCHD, and prostaglandins administration is required. These can be used intravenously, and in emergency situations, by intraosseous route 20,24 . If the patient is cyanotic without acidosis, prostaglandins should be started at $5-10 \mathrm{ng} / \mathrm{kg} / \mathrm{min}$; if the response is poor, the dose should be increased to the double (maximum dose: $100 \mathrm{ng} / \mathrm{kg} / \mathrm{min}$ ) every 20 minutes until clinical improvement is achieved with $\mathrm{SaO}_{2}$ between 75 and $85 \%$, or saturations $<70 \%$ with lactate $<2 \mathrm{mmol} / \mathrm{L}$. In the case of cyanotic patients with weak femoral pulses without acidosis, treatment with prostaglandins is similar. In patients with suspected CCHD and acidosis, prostaglandins initial dose is $50 \mathrm{ng} / \mathrm{kg} / \mathrm{min}$, with high doses (100-200 $\mathrm{ng} / \mathrm{kg} / \mathrm{min}$ ) possibly being required while deciding whether interventional or surgical management is necessary. Infusion can be reduced by $25-50 \mathrm{ng} / \mathrm{kg} / \mathrm{min}$ with rapid improvement, but this is usually done after cardiologic evaluation ${ }^{20}$. The parameters that should be monitored include 


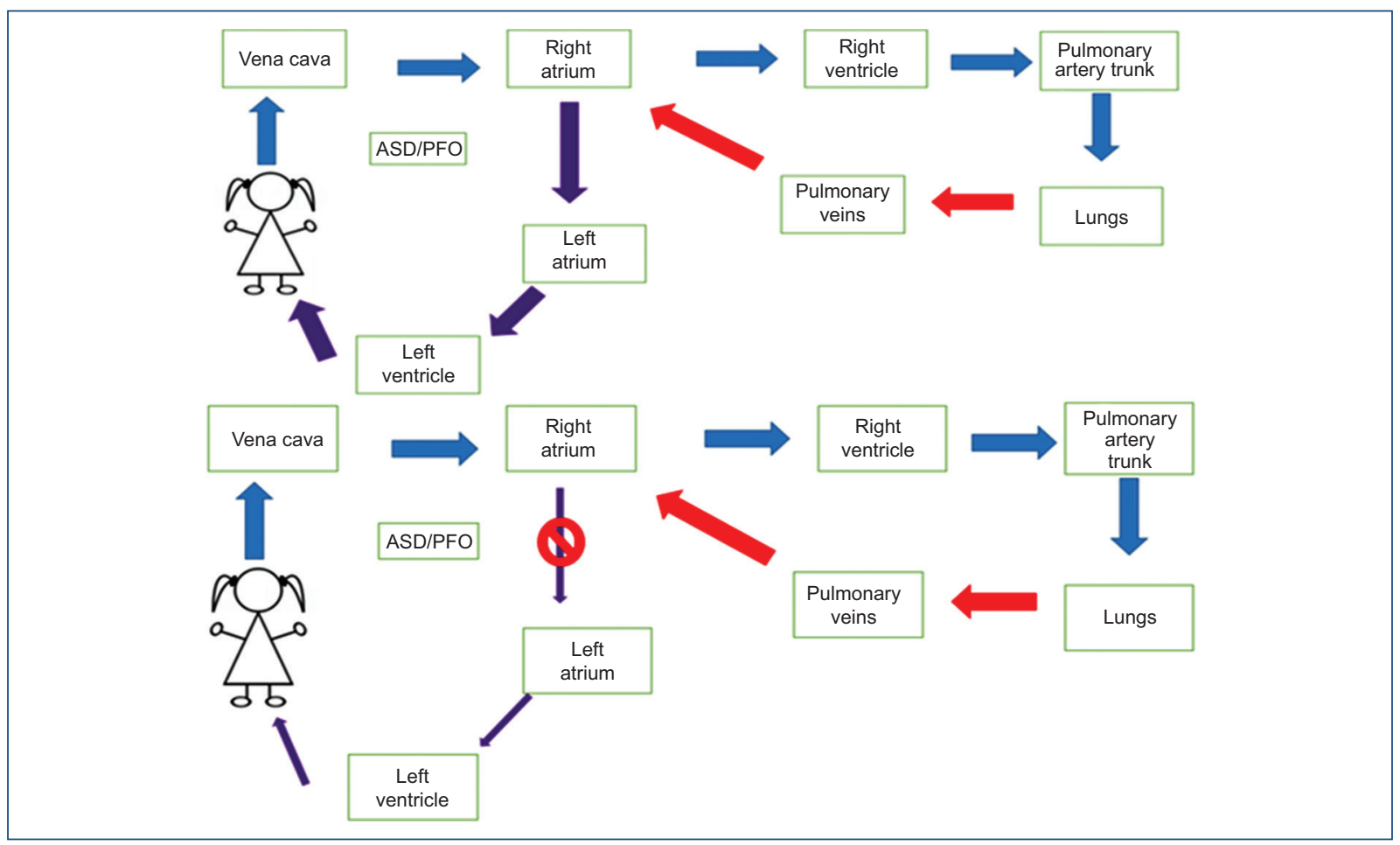

Figure 3. The pathophysiology of a patient with total anomalous pulmonary venous return in which systemic cardiac output depends on an atrial septal defect is shown at the top. At the bottom, the pathophysiology of a patient with TAPVR with a small ASD that causes low cardiac output and acute pulmonary edema is shown. Infra-cardiac TAPVR: infracardiac total anomalous pulmonary venous return; ASD/PFO: atrial septal defect/patent foramen ovale.

heart rate, blood pressure, $\mathrm{SaO}_{2}$, respiratory rate, temperature and arterial blood gas monitoring. Main adverse effects include bradycardia, apneas and hypotension, which is why keeping the patients in an intensive care unit is advised ${ }^{22}$.

Patients with happy tachypnea have pulmonary hyperflow $\mathrm{CHD}$ with risk of heart failure; management is based on loop diuretics, aldosterone antagonists, angiotensin-converting enzyme inhibitors (ACEI) and beta-blockers. It is common for this group to develop pulmonary hypertension due to hyperflow, which some may confuse with pulmonary hypertension due to elevated pulmonary resistances and administer pulmonary vasodilators, thus causing higher hyperflow, increased preload, heart failure and, in severe cases, acute pulmonary edema; therefore, the management focuses on controlling the heart failure.

It should be borne in mind that patients with happy cyanosis are those in whom cyanosis onset is late (at more than 5 weeks); they do not exhibit data of respiratory failure and some may also show data consistent with volume overload. It is important to refer them for cardiologic evaluation in order for proper management to be indicated. Figure 1 summarizes the types of $\mathrm{CHD}$ based on clinical presentation and management.

\section{Clinical case 1}

Newborn who hours after birth had respiratory distress and data consistent with low cardiac output. Respiratory distress increased, requiring endotracheal intubation; $\mathrm{SaO}_{2}$ was $<75 \%$ with $\mathrm{FiO}_{2}$ at $100 \%$. No murmurs were auscultated, and pulses were not palpable. X-ray without cardiomegaly and with pulmonary venous congestion; echocardiogram reported TAPVR with restrictive atrial septal defect. Prostaglandins were administered and atrial septostomy was performed (Fig. 3).

\section{Clinical case II}

Twelve-day-old newborn with data consistent with low cardiac output, delayed capillary filling and non-palpable pulses. X-ray with cardiomegaly and pulmonary 


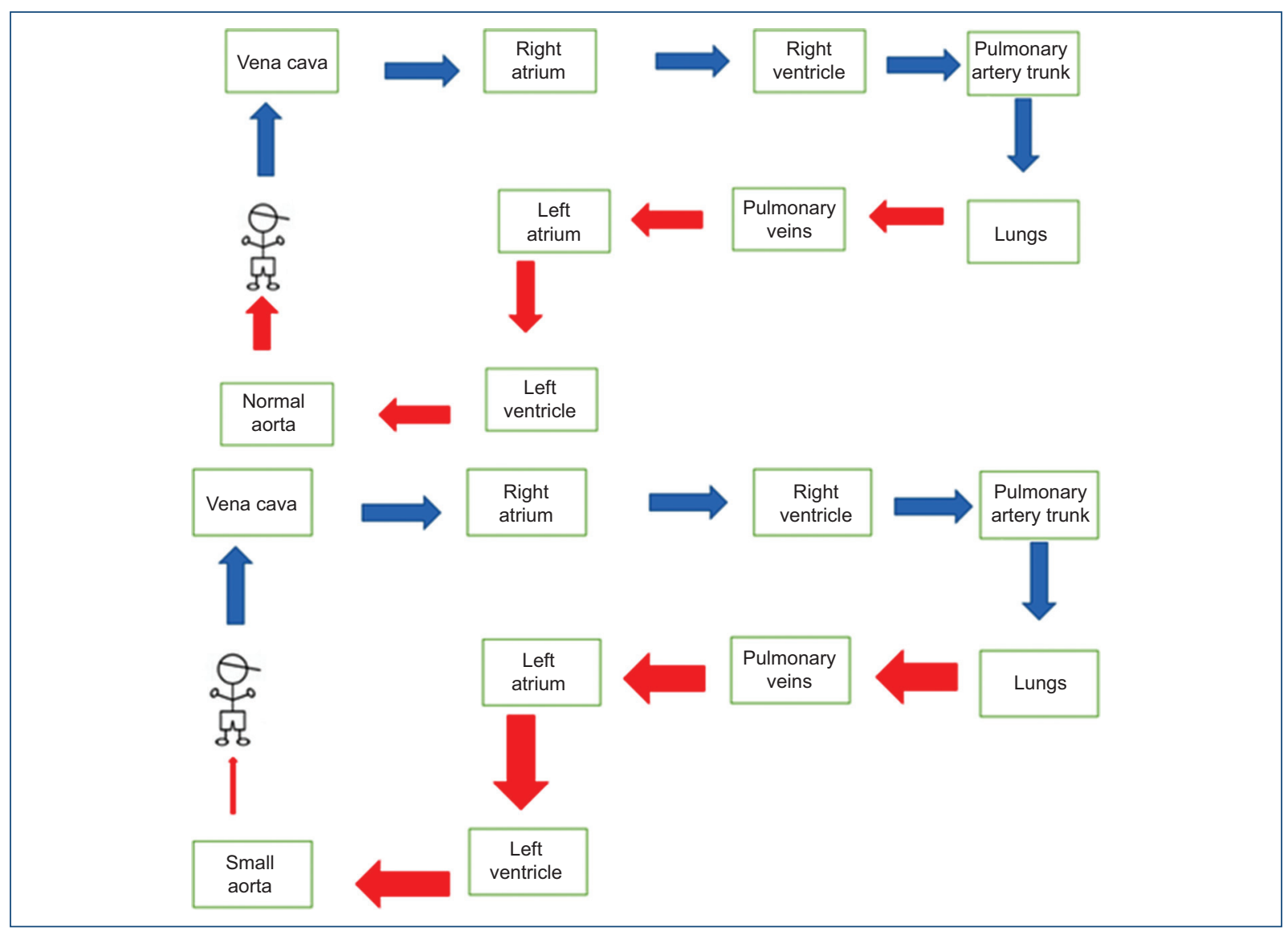

Figure 4. At the top, flow is normal. The bottom part shows coarctation of the aorta with decreased systemic cardiac output and, therefore, with left ventricular failure and, subsequently, acute pulmonary edema. X-ray showed significant cardiomegaly at the expense of the left ventricle with significant pulmonary hyperflow.

hyperflow; echocardiogram reported critical coarctation of the aorta (Fig. 4). Prostaglandins were administered and urgent cardiac catheterization was carried out.

\section{Infant stage}

CHDs characteristics are modified by hemodynamic changes, with the most important being a decrease in pulmonary vascular resistances (after 3 weeks of age), which causes an increase in CHDs symptomatology with pulmonary hyperflow.

CHDs are classified based on their pathophysiology. First, the presence or not of cyanosis is determined and, subsequently, pulmonary flow on chest X-ray. To determine if an X-ray is appropriate, it should be established if it is during inspiration, showing the trachea and central bronchi, and if some discs and vertebral bodies can be observed behind the heart, this indicates that the film has an adequate exposure (neither hard nor soft). If the upper abdomen and shoulders are visualized, it is technically correct. The basic elements to assess the cardiac silhouette on an X-ray are liver and gastric bubble localization, apex and cardiac mass localization, assessment of bronchial anatomy, presence or not of cardiomegaly and pulmonary flow. The latter can be increased, decreased or normal. An increased pulmonary flow indicates $p Q>s Q$ (Fig. 2), a decreased pulmonary flow indicates $p Q<s Q$ (Fig. 2), and normal pulmonary flow, $\mathrm{Qp}=\mathrm{Qs}$, i.e., there are no intracardiac shunts as in valvular disease (Fig. 2).

Once we know the type of pulmonary flow and presence or not of cyanosis, CHDs are classified into:

- CHDs with cyanosis, which increases with crying or exertion. They are subdivided in two based on pulmonary flow:

- Increased. These are CHDs with mixed shunt such as TAC, TGA with ventricular septal defect (Fig. 5). Management of these patients generally must be indicated by the cardiologist. 


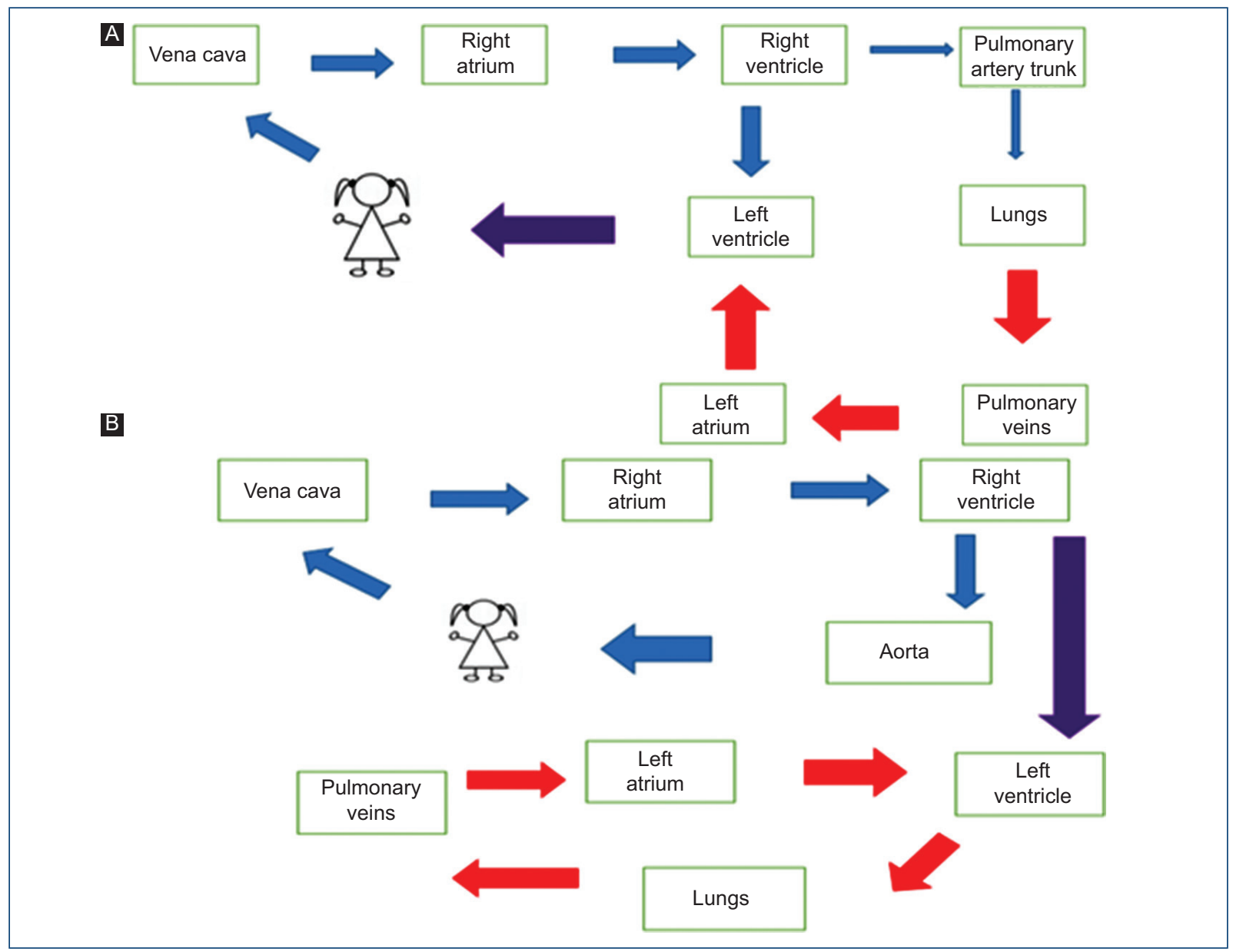

Figure 5. A: Tetralogy of Fallot pathophysiology. A decrease in pulmonary flow (passage from right ventricle to the pulmonary artery trunk) and right-to-left shunt at the ventricular level are observed. B: Transposition of the great arteries pathophysiology, where parallel circulation with ventricular shunt is observed at the ventricular level

- Decreased. These are CHDs with right-to-left shunt with pulmonary valve obstruction, with the main one being TOF (Fig. 5). Diuretics and fluid restriction should be avoided.

- CHDs without cyanosis, which are divided in two subtypes based on pulmonary flow:

- Increased. These include CHDs with left-to-right shunt $(p Q>s Q)$, and have increased pulmonary flow and cardiomegaly. The most common is patent ductus arteriosus, ventricular septal defect (Fig. 6). These pathologies can occur with clinical data consistent with heart failure, with data indicating respiratory distress with pulmonary rales being found on physical examination. It is common for hepatomegaly to be present; in fact, liver examination should be mandatory in every patient with evidence of respiratory distress within the first month of life ${ }^{7}$.
Management includes beta-blocker, ACEI and diuretic ${ }^{25}$.

- Normal pulmonary flow. These CHDs have no shunt or cardiomegaly, or it is minimal. Valvular heart diseases such as aortic or pulmonary stenosis are included in this category (Fig. 6).

\section{Conclusion}

CHDs constitute a global public health problem ${ }^{2,3}$. Despite all advances in pediatric cardiology, the most important is for the patient to be timely detected and referred. Some of the key points that can be concluded include:

- In a patient with cardiogenic shock within the first 72 hours of life, the existence of a CCHD should always be suspected. Even if echocardiographic assessment 


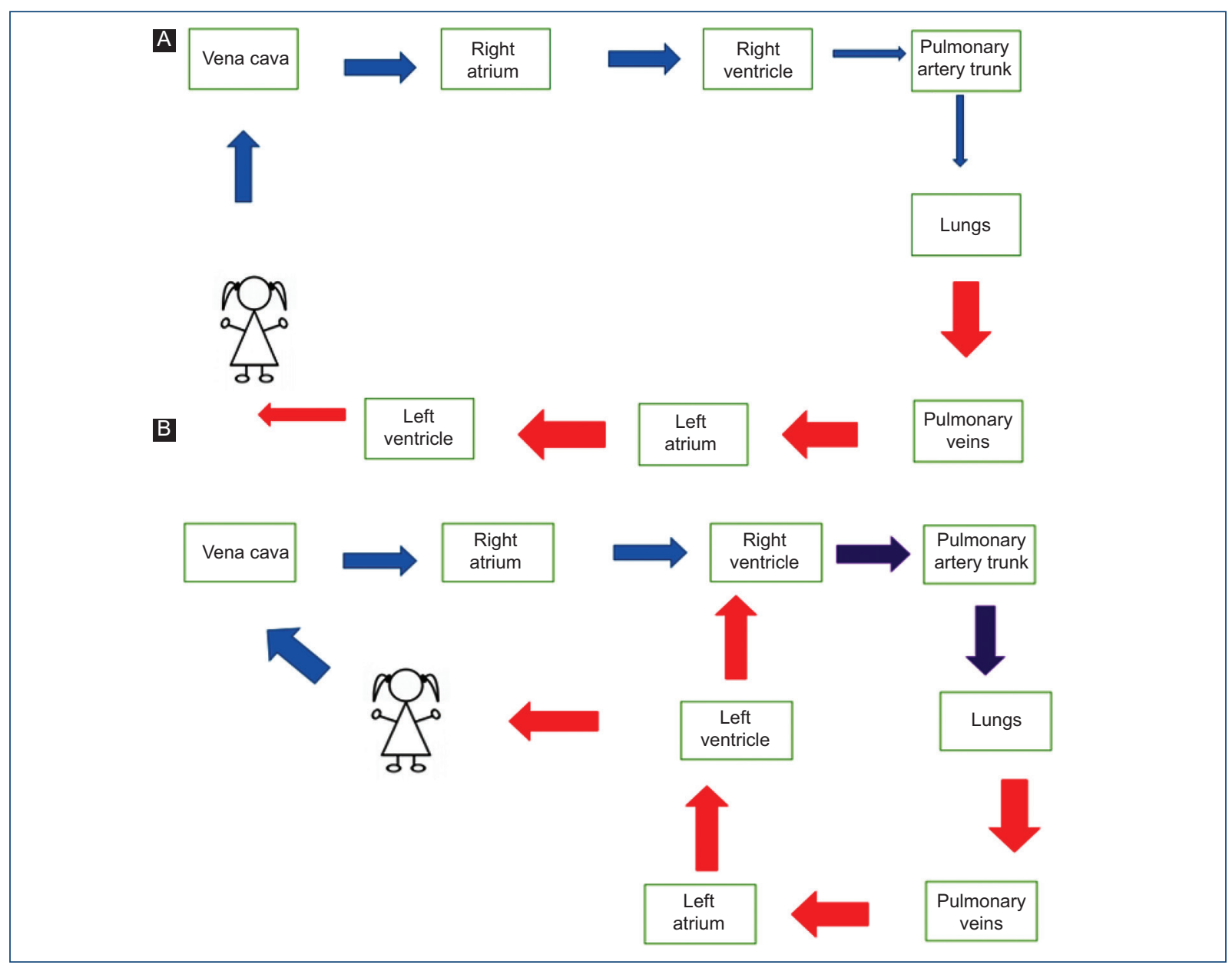

Figure 6. A: Pathophysiology of aortic stenosis. The aortic valve is with stenosis; however, since there is no shunting, pulmonary flow is not affected. B: Ventricular septal defect. Left-to right-shunt is observed, which causes an increase in pulmonary flow $\mathrm{p} 0$.

is not available, it is essential to initiate prostaglandins administration ${ }^{25}$.

- If decreased pulmonary flow is found in a neonate, prostaglandins are required. If pulmonary flow is normal or increased, accompanied by hepatomegaly and data consistent with low systemic cardiac output (cold and wet shock) on physical examination, atrial septostomy is required. In case there is no low systemic cardiac output, a diuretic with ACEI should be initiated.

- It is important for cardiologic screening to be implemented for timely detection of these patients.

- Patients with CHD with left-to-right shunt can usually be corrected with a low mortality if operated on at the right time. However, a common problem is late referral of some of these patients, which causes for them to become inoperable or operable with high risk ${ }^{23}$. Therefore, it is important that each pediatrician performs an adequate evaluation with timely referral of these patients to a hospital for their care.

\section{Funding}

We did not receive any type of funding.

\section{Conflicts of interest}

The authors declare that they have no conflicts of interest.

\section{Ethical disclosures}

Protection of human and animal subjects. The authors declare that no experiments have been performed on humans or animals for this research. 
Confidentiality of data. The authors declare that they have followed the protocols of their work center on the publication of patient data.

Right to privacy and informed consent. The authors have obtained informed consent from the patients and/or subjects referred to in the article. This document is in the possession of the corresponding author.

\section{References}

1. Van der Bom T, Zomer AC, Zwinderman AH, Meijboom FJ, Bouma BJ, Mulder BJ. The changin epidemiology of congenital heart disease. Nat Rev Cardiol. 2011;8(1):50-60.

2. Calderón-Colmenero J, Cervantes-Salazar JL, Curi-Curi PJ, Ramírez-Marroquín S. Problemática de las cardiopatías congénitas en México. Propuesta de regionalización. Arch Cardiol Mex. 2010;80(2):133-40.

3. Peña-Juárez RA, Medina-Andrade MA. Situación real de las cardiopatías congénitas en dos hospitales públicos del estado de Jalisco. Arch Cardio Mex. 2019;89(4):1-7.

4. Hoffman Jl, Kaplan S. The incidence of congenital heart disease. J Am Coll Cardiol. 2002;39(12):1890-900.

5. Marelli Aj, Mackie AS, lonescu-Ittu R, Rahme E, Pilote L. Congenital hear disease in the general population: Changing prevalence and age distribution. Circulation. 2007;115(2):163-72.

6. Aranguren Bello HC, Londoño Trujillo D, Troncoso Moreno GA, Dominguez Torres MT, Taborda Restrepo Aa, Fonseca A, et al. Oximetry and neonatal examination for the detection of critical congenital heart disease: a systematic review and meta-analysis. F1000Res. 2019;8:242.

7. Dolbec K, Mick NW. Congenital heart disease. Emerg Med Clin North Am. 2011;29(4):811-27.

8. Dawson A, Cassell CH, Riehle-Colarusso T, Scott DG, Tanner JP, Russell SK, et al. Factors associated with late detection of critical congenital heart disease in newborns. Pediatric. 2013;132(3):e604-11.

9. Peña-Juárez RA, Chávez Sáenz JA, García-Canales A, Medina-Andrade M Martínez-Gonzalez MT, Gutiérrez-Cobian L, et al. Comparación de oxímetros para detección de cardiopatías congénitas críticas. Arch Cardiol Mex. 2019;89(2):172-80.
10. Dhandayuthapani G, Chakrabarti S, Ranasinghe A, Hunt L, Grant D, Martin RP, et al. Short-term outcome of infants presenting of pediatric intensive care unit with new cardiac diagnoses. Congenit Heart Dis. 2010;5:444-49.

11. Nasr VG, DiNardo JA. Pulse oximetry. Pediatr Rev. 2019;40(11):605-8.

12. Teitel D. Recognition of undiagnosed neonatal heart disease. Clin Perinatol. 2016;43(1):81-98.

13. Kumar KR, Kirsch RE, Hornik CP. Cardiovascular physiology for intensivists. En: Ungerleider Ross M, editor. Critical heart disease in infants and children. Third edition. Elsevier; 2019. pp 111-133.

14. Marín Rodríguez C, Sánchez Alegre ML, Lancharro Zapata A, Alarcón Rodríguez J. Cuantificación de la circulación pulmonar y sistémica: Qp/ Qs. Qué es, cómo se calcula y para qué sirve. Lo que el radiólogo debe saber. Radiología. 2015;57(5):369-79.

15. Riera Kinkel C. Actualidades en el tratamiento quirúrgico de las cardiopatías congenitas. Rev Mex Pediatr. 2010;77(5):214-23.

16. Desai K, Rabinowitz EJ, Epstein S. Physiologic diagnosis of congenita heart disease in cyanotic neonates. Curr Opin Pediatr. 2019;31:274-83.

17. Martín Escribano P. Semiología de la cianosis. Arch de bronconeumol 1974; 10(2): 80-81)

18. Sarris GE, Balmer C, Bonou P, Comas JV, da Cruz E, Di Chiara L, et al. Clinical guidelines for the management of patients with transposition of the great arteries with intact ventricular septum. Eur J Cardiothorac Surg. 2017;51(1):e1-e32.

19. Patiño Bahena EJ, Calderón Colmenero J, Buendía Hernández A, Attie F. Conexión anómala total de venas pulmonares. En: Attie M, editor. Cardiología pediátrica. 2. a edición. Panamericana; 2012. pp. 92- 101.

20. Singh $Y$, Mikrou $P$. Use of prostaglandins in duct-dependent congenita heart conditions. Arch Dis Child Educ Pract Ed. 2018;103(3):137-40.

21. Aortopulmonary septal defects and patent ductus arteriosus, total anomalous pulmonary venous return, transposition of the great arteries, tetralogy of Fallot with and without pulmonary atresia, hypoplastic left heart syndrome. En: Nichols DG, Ungerleider RM, Spevak PJ, et al. Critical heart disease in infants and children. 2nd ed. Philadelphia, PA: Mosby; 2006. Págs. 652-60.

22. Maroto $C$, Camino M, Girona JM, Malo $P$, Romera G, Zunzunegui JL. Recién nacido con sospecha de cardiopatía congénita. Protocolos Diagnóstico Terapéuticos de la AEP: Neonatología. Rev Esp Cardiol. 2008;54:49-66.

23. Vijayalakshmi IB. Evaluation of left to right shunts by pediatrician: How to follow, when to refer for intervention? Indian J Pediatr. 2015;82(11):1027-32.

24. Mikrou $P$, Singh $A$, Singh $Y$. Prostaglandin infusion Guideline. Eur J Pediatr 2015; 154:700-7.

25. Parvathi UI, Moreno Guillermo E, Caneo LF, Faiz T, Shekerdeian LS, lyer KS. Management of late presentation congenital heart disease. Cardiol Young. 2017;27:6:s31-39. 